\title{
From the Editor: Expanding Our Frames of Reference
}

\author{
Dorothy S. Becvar
}

Published online: 6 June 2009

(C) Springer Science+Business Media, LLC 2009

Marriage and family therapists (MFTs) who assume a non-linear frame of reference are challenged in their efforts to be systemically consistent as they do therapy and conduct research in a society that operates primarily according to a linear world view. Typically, problems and perceptions of reality are narrowly defined in such a context, and efforts to operate from a different paradigm are not widely accepted. However, there are many ways in which to strive for self-referential consistency, one of which is the theme of this editorial.

In order to avoid committing what Churchman (1979) termed the "environmental fallacy," or failing to take into account the larger context consistent with which problems are perceived and experienced, systemically oriented therapists and social scientists are advised to take a broader view than typically is employed by those who operate from other perspectives. Ideally, systemic researchers thus seek to expand the boundaries of the problem under study to encompass relevant aspects of the environment in which that problem exists, and to expand their frameworks of belief to encompass more pieces of the systemic whole of which we all are assumed to be a part (Becvar and Becvar 2009). In keeping with such an orientation, this issue includes several exemplifications of work characterized by expanded frames of reference. Each article thus offers a new view of some older ways of thinking about marriage and family therapy and/or of doing science relevant to the field.

In the first article, "On Yoda, Trouble, and Transformation: The Cultural Context of Therapy and Supervision," Vincent Ward invites therapists and supervisors to go beyond their usual conceptions of themselves and to recognize that they have been 'drafted... into the role of Cultural Elder.' The next article, "What Children Feel About Their First Encounter with Child and Adolescent Psychiatry." authored by Monica Hartzell, Jaakko Seikkula, and Anne-Liis von Knorring, shifts our focus to children's perceptions of therapy, a topic that previously has not received a great deal of attention. Then, similar in terms of its relatively unique focus and methodology, Amy Wickstrom explores "The Process of Systemic Change in Filial Therapy: A Phenomenological Study of Parent Experience."

D. S. Becvar $(\bowtie)$

Saint Louis University, St. Louis, MO, USA

e-mail: becvard@aol.com; becvards@slu.edu 
In the fourth article, "Reconsidering the Term "Marriage" in Marriage and Family Therapy," Christine Murray and Thomas Murray discuss the pros and cons of a name change for the field as a whole, inviting others to participate in conversations related to this topic. And finally, in the article that concludes this issue, "Remembering the Pattern that Connects: Toward an Eco-Informed MFT," Tracy Laszloffy encourages all of us to expand our frameworks by including a greater awareness of ecological resources and issues both in the training of therapists and in our work with clients. And so we come full circle, with an emphasis on expanded frames of reference that may enable us not only to be more systemically consistent but also to access different perceptions that may increase our effectiveness as MFTs.

\section{References}

Becvar, D. S., \& Becvar, R. J. (2009). Family therapy: A systemic integration (7th ed.). Boston: Allyn \& Bacon.

Churchman, D. (1979). The systems approach and its enemies. New York: Basic Books. 